\title{
Conservative management with Carnoy's solution in ameloblastoma involving two unerupted teeth: a report of two cases
}

\author{
Sang Min Lee ${ }^{1}$, Jeong-Kui Ku², Dae Ho Leem ${ }^{1,3}$, Jin-A Baek ${ }^{1,3}$, Seung-O Ko ${ }^{1,3,4}$ \\ ${ }^{1}$ Department of Oral and Maxillofacial Surgery, School of Dentistry, Jeonbuk National University, Jeonju, ${ }^{2}$ Department of Oral and \\ Maxillofaical Surgery, Section of Dentistry, Armed Forces Capital Hospital, Seongnam, ${ }^{3}$ Research Institute of Clinical Medicine of \\ Jeonbuk National University-Biomedical Research Institute of Jeonbuk National University Hospital, \\ ${ }^{4}$ Institute of Oral Bioscience, School of Dentistry, Jeonbuk National University, Jeonju, Korea
}

\begin{abstract}
J Korean Assoc Oral Maxillofac Surg 2021;47:40-46)
Marsupialization is widely used as a primary treatment modality for reducing size of large cysts. However, there is no recommendation for specific duration of marsupialization. In addition, Carnoy's solution usually is applied at the time of enucleation as a fixative agent. In this report, we present an appropriate marsupialization duration of ameloblastoma involving two unerupted teeth. In this present study, marsupialization using a Foley catheter was performed in two cases of ameloblastoma of the mandible involving two adjacent impacted teeth. Carnoy's solution was applied for 3-5 minutes after enucleation in both patients. Periodically during marsupialization, the size of the radiolucency was measured in panoramic view, and clinical examination was performed. No remarkable paresthesia or soft tissue injury was observed after application of Carnoy's solution or during follow-up. We recommend 12 to 16 weeks as an adequate marsupialization duration for a large ameloblastoma involving two impacted teeth based on increased radiopacity along the margins of the lesions. Poor oral hygiene was an issue after 12 weeks of marsupialization in one case. There were no remarkable complications with Carnoy's solution in either case. The Foley tube has a two-way system that is more effective for irrigating the cavity than is the conventional one-way system.
\end{abstract}

Key words: Ameloblastoma, Decompression, Carnoy's solution, Conservative treatment

[paper submitted 2019. 2. 26 / revised 2019. 5. 29 / accepted 2019. 6. 3]

\section{Introduction}

Ameloblastoma is a commonly observed benign tumor in the oral and maxillofacial region that is derived from dental epithelium ${ }^{1}$. In 2005, the World Health Organization (WHO) defined ameloblastoma as a benign, slow-growing, but locally-invasive and polymorphic neoplasm of dental epithelium proliferation ${ }^{2,3}$. If it is not completely removed, it tends to recur at a rate of $60 \%$ to $80 \% \%^{2,4-7}$. There is no report of sex predilection, and it occurs most commonly in the mandible ${ }^{8}$.

\section{Seung-O Ko}

Department of Oral and Maxillofacial Surgery, School of Dentistry, Jeonbuk National University, 567 Baekje-daero, Deokjin-gu, Jeonju 54896, Korea

TEL: +82-63-250-2211

E-mail: omfskso@jbnu.ac.kr

ORCID: https://orcid.org/0000-0001-7504-7557

(c) This is an open-access article distributed under the terms of the Creative Commons Attribution Non-Commercial License (http://creativecommons.org/ licenses/by-nc/4.0/), which permits unrestricted non-commercial use, distribution, and reproduction in any medium, provided the original work is properly cited.

Copyright (C) 2021 The Korean Association of Oral and Maxillofacial Surgeons. All rights reserved.
In 1933, Carnoy's solution was described as a sclerosing agent for treatment of cyst and fistula ${ }^{6}$, and it is still used as a fixative agent ${ }^{9}$. In 1987, Carnoy's solution was applied in unicystic ameloblastoma (UAB) by Stoelinga and Bronkhorst and has been recently used to reduce the risk of recurrence after conservative treatment of $\mathrm{UAB}^{10}$.

Gao et al. ${ }^{4}$ reported that marsupialization is an effective primary treatment for reducing the size of dental cysts and promoting bone generation. Decompression has been suggested when the lesion exceeds $3 \mathrm{~cm}^{2}$ in the panoramic view. In general, marsupialization reduces the size of cysts and minimizes disturbances, resulting in promotion of eruption of involved teeth; reducing issues with surrounding anatomical structures such as the inferior alveolar nerve and maxillary sinus; and preventing pathologic fracture during enucleation ${ }^{1}$.

In this present study, we report a common effective duration for marsupialization and discuss the treatment outcome after enucleation using Carnoy's solution in two patients who had large $\left(>3 \mathrm{~cm}^{2}\right)$ radiolucent lesions with unerupted mandibular second and third molars. 

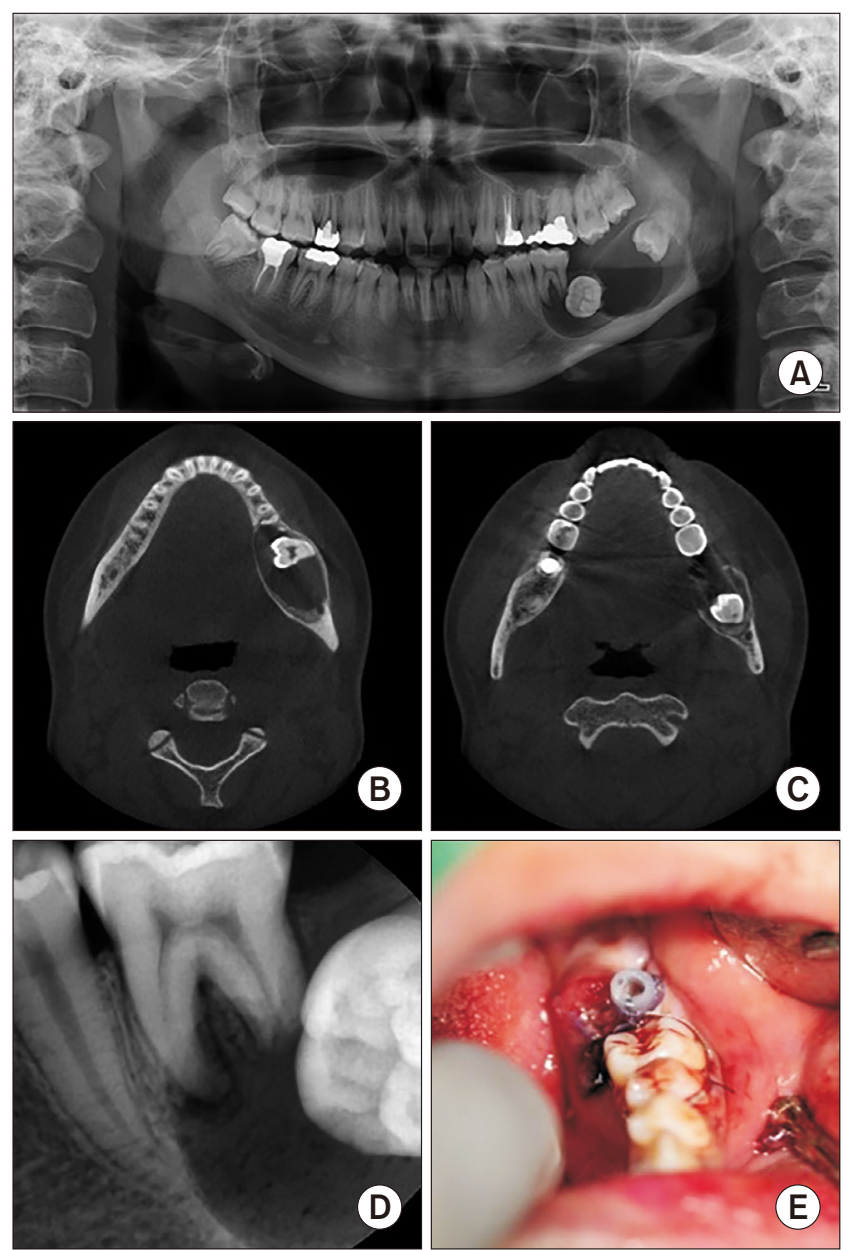

Fig. 1. A. Panoramic view on the first visit $(4.2 \mathrm{~cm} \times 2.0 \mathrm{~cm})$. B, C. Computed tomography coronal view on the first visit. D. Periapical standard radiograph on the first visit. E. Intraoral photo just after marsupialization using the Foley tube.

Sang Min Lee et al: Conservative management with Carnoy's solution in ameloblastoma involving two unerupted teeth: a report of two cases. J Korean Assoc Oral Maxillofac Surg 2021

\section{Cases Report}

\section{Case 1}

An 18-year-old female presented to our hospital with a chief complaint of unerupted left lower second molar and induration of the left side of the floor of the mouth. Oral examination showed unerupted left mandibular second and third molars, and the left lingual side of the posterior mandible exhibited mild swelling, induration, and redness, but no discomfort or tenderness was reported. There was mobility of the left mandibular first molar but no pain. In panoramic view, the left mandibular second and third molars were impacted, and a large radiolucent lesion (approximately 4.2 $\mathrm{cm} \times 2.0 \mathrm{~cm}$ ) was visualized around that area.(Fig. 1)

Marsupialization was performed on the buccal vestibule of the unerupted mandibular second molar.(Fig. 2) During the two-week follow-up period, neoplasm formation persisted, and ameloblastoma was diagnosed by incisional biopsy. Ten weeks after marsupialization, new bone formation was observed as increased radiopacity on the anterior and superior borders of the lesion in panoramic view.(Fig. 3) Fifteen weeks after marsupialization, woven bone density was increased in the margin of the lesion compared to the panoramic view at 10 weeks. However, since there was no significant change in the size of the cavity, enucleation was planned.

Twenty weeks after marsupialization, the intra-oral rubber drain was removed. At 21 weeks after marsupialization, cyst enucleation and extraction of the left mandibular first, second, and third molars were performed under general anesthesia. Distal root resorption in the left mandibular first molar was confirmed through radiographic imaging. Cyst enucleation was performed, consisting of the main mass of $4.5 \mathrm{~cm} \times 2 \mathrm{~cm}$, a small mass of $2 \mathrm{~cm} \times 1.5 \mathrm{~cm}$, and multiple inflammatory tis-
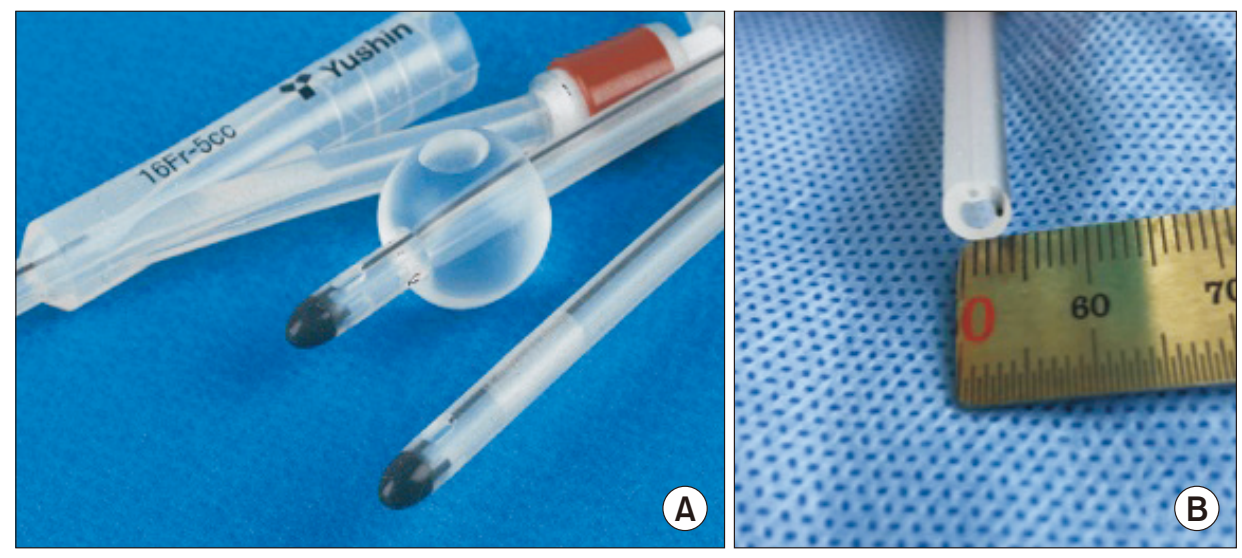

Fig. 2. A. 16-Fr Foley catheter (Yushin Medical \& Trading). B. Cross-section of the Foley catheter.

Sang Min Lee et al: Conservative management with Carnoy's solution in ameloblastoma involving two unerupted teeth: a report of two cases. J Korean Assoc Oral Maxillofac Surg 2021 
sues.(Fig. 4) Carnoy's solution (30 mL of 100\% ethanol, 15 $\mathrm{mL}$ of $100 \%$ chloroform, and $5 \mathrm{~mL}$ of $100 \%$ acetic acid) was applied for approximately 3 minutes starting from the last entry site, followed by washing with normal saline. The surgical site was packed with furacin gauze without primary closure.

Plexiform ameloblastoma was diagnosed from permanent biopsy. The surgical site was continuously packed with furacin gauze. After seven weeks of cyst enucleation, an epithelized soft tissue cavity of $1 \mathrm{~cm} \times 2.5 \mathrm{~cm}$ was observed. No paresthesia on the left lower lip area and no recurrence of the lesion were observed during the follow-up period of eight
months.(Fig. 5)

\section{Case 2}

A 17-year-old male presented to our hospital with a chief complaint of unerupted right mandibular second molar and painful swelling in the right buccal area. Oral examination showed that the right mandibular second and third molars were unerupted, with no remarkable mobility of the right mandibular first mola, but mild discomfort during percussion testing. In panoramic view, there was a large (approximately
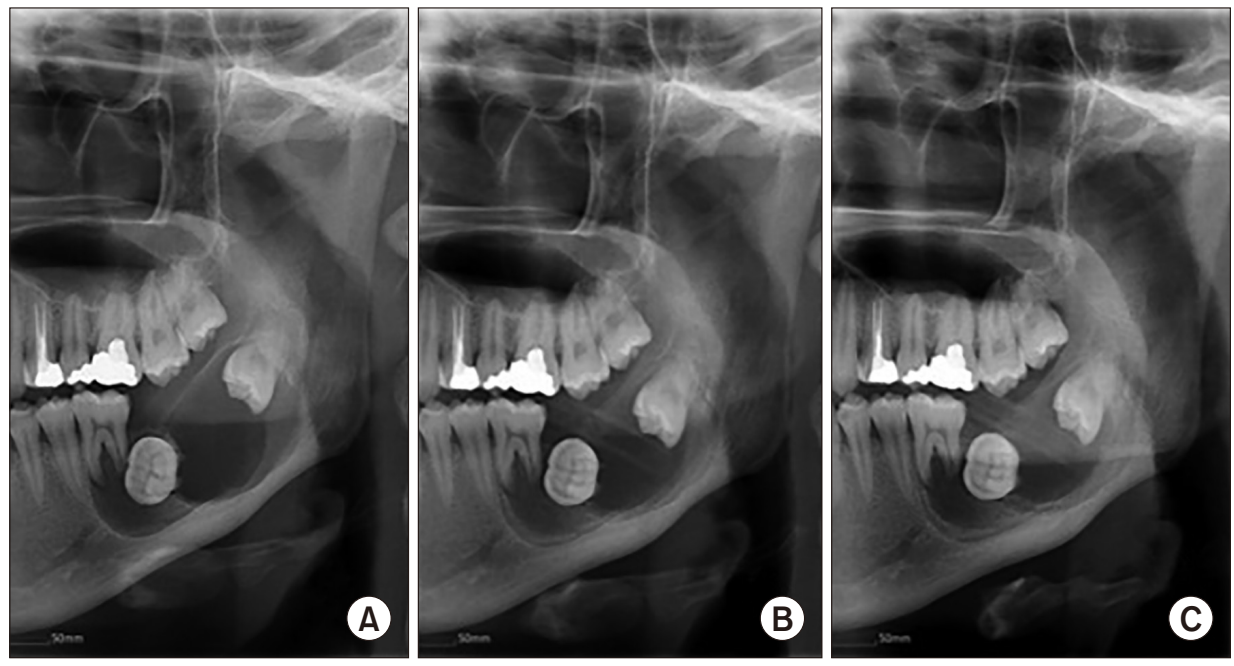

Fig. 3. Panoramic view at (A) first visit, (B) 10 weeks after marsupialization, and (C) 15 weeks after marsupialization. Sang Min Lee et al: Conservative management with Carnoy's solution in ameloblastoma involving two unerupted teeth: a report of two cases. J Korean Assoc Oral Maxillofac Surg 2021
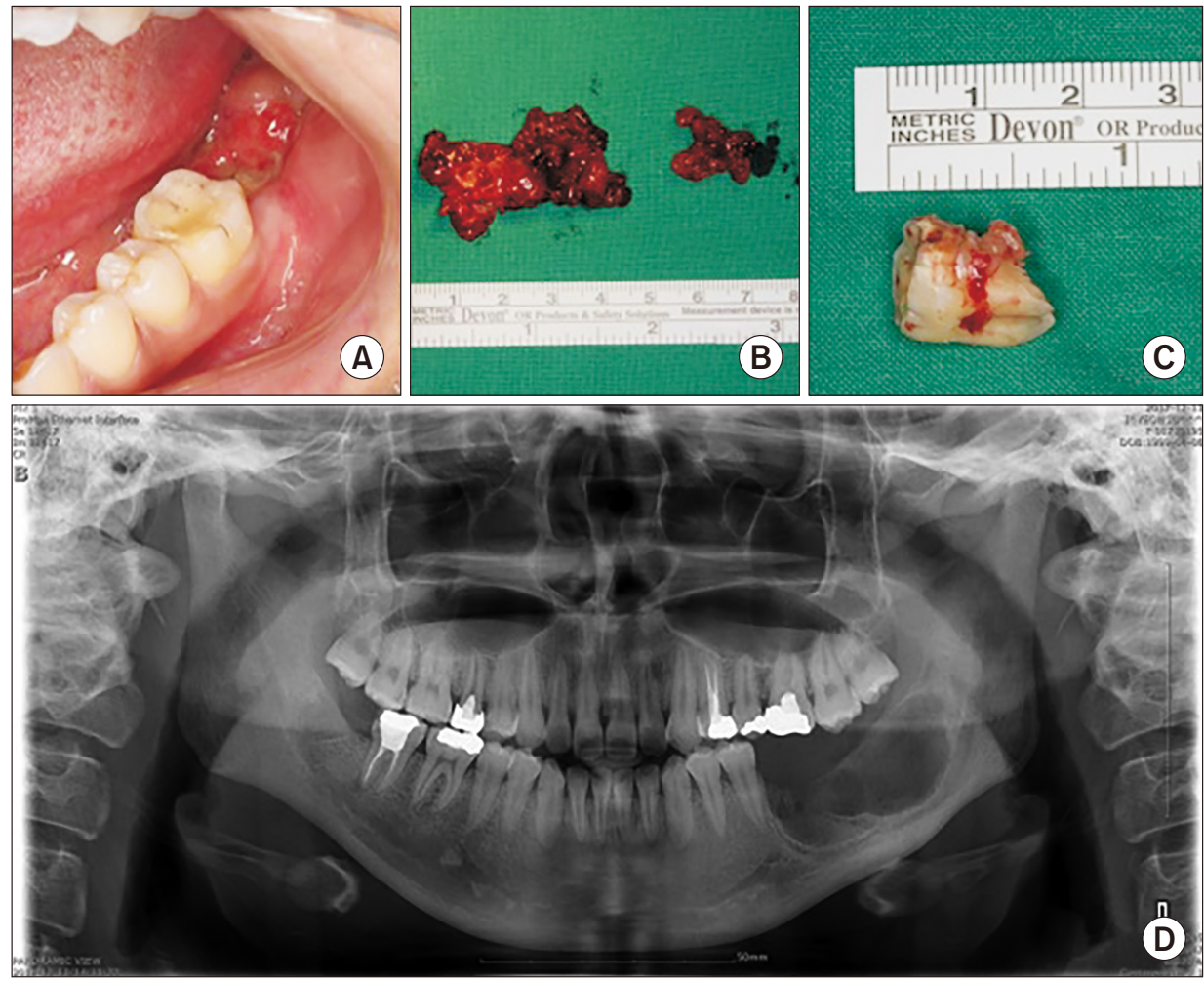

Fig. 4. A. Preoperative intraoral lesion. B. Removal of the main mass $(4.5$ $\mathrm{cm} \times 2 \mathrm{~cm})$ and small mass $(2 \mathrm{~cm} \times 1.5$ $\mathrm{cm})$. C. \#46 distal root resorption. D. Postoperative panoramic view. Sang Min Lee et al: Conservative management with Carnoy's solution in ameloblastoma involving two unerupted teeth: a report of two cases. J Korean Assoc Oral Maxillofac Surg 2021 

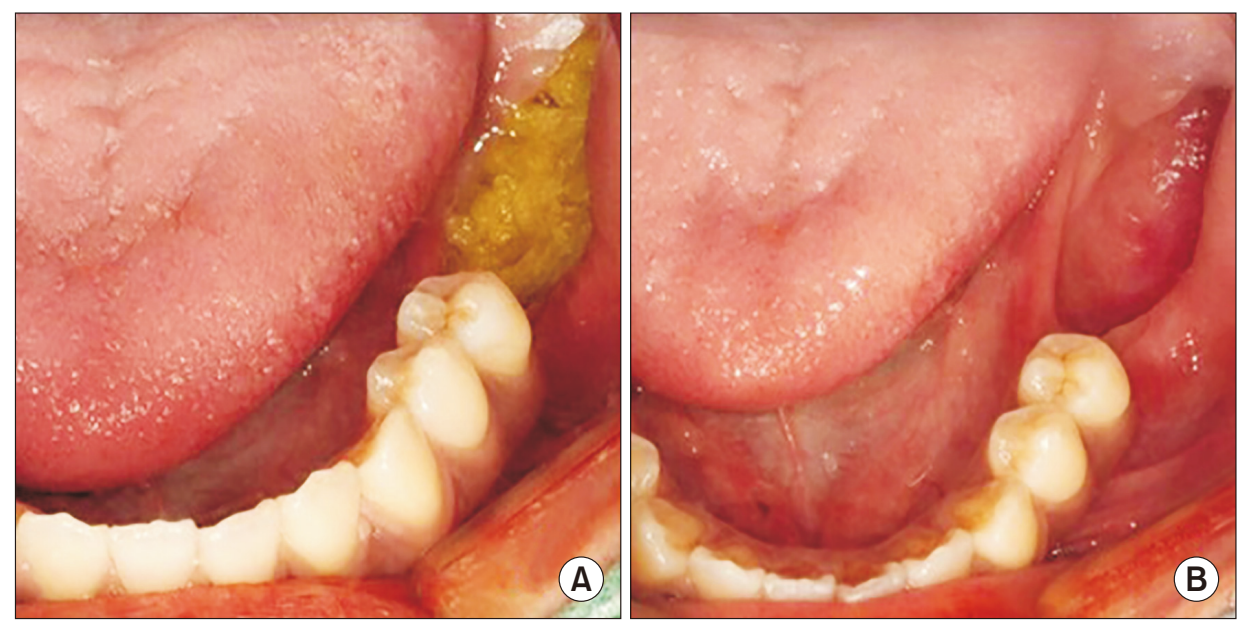

Fig. 5. A. Open dressing with furacin gauze was changed twice a week. B. Seven weeks after enucleation.

Sang Min Lee et al: Conservative management with Carnoy's solution in ameloblastoma involving two unerupted teeth: a report of two cases. J Korean Assoc Oral Maxillofac Surg 2021
$4.5 \mathrm{~cm} \times 8.1 \mathrm{~cm}$ ) radiolucent lesion around the impacted right mandibular second and third molars. Right mandibular cortical bone was flattened and dilated, and the lower border of the mandible was very thin on computed tomography (CT). (Fig. 6) During incisional biopsy, marsupialization with a Foley catheter (16 Fr, 5 mL, 2 way; Yushin Medical \& Trading, Bucheon, Korea) was initiated, and UAB was diagnosed from biopsy.

Seven weeks after marsupialization, radiopacity increased on the superior border of the lesion, and woven bone formation was observed in the margin of the lesion in panoramic view. Sixteen weeks after marsupialization, radiopacity continued to increase on the superior border of the lesion, but there was no significant change in size on panoramic view.(Fig. 7) Twenty-one weeks after marsupialization, cyst enucleation was planned since the size of the lesion was not significantly different from the previous panoramic view.

Through 12 weeks of marsupialization, no remarkable clinical findings were observed. However, after that time, relatively transparent yellowish fluid was observed, and antibiotics were administered for one week. Sixteen weeks after marsupialization, there was no significant change in bone formation on radiograph. Continual infectious yellowish fluid and poor oral hygiene around the tube were observed. The area contained a main mass of $4 \mathrm{~cm} \times 5.5 \mathrm{~cm}$ and a small mass of $2 \mathrm{~cm} \times 2.5 \mathrm{~cm}$.(Fig. 8) After mass removal, Carnoy's solution was applied to the cavity for 3 minutes beginning from the last entry site, followed by washing with normal saline. UAB was diagnosed by permanent biopsy.

Twenty-two weeks after enucleation, panoramic view showed increased radiopacity at the anterior, posterior, and inferior borders of the mass removal area. New bone formation was observed along the margin of the enucleation site

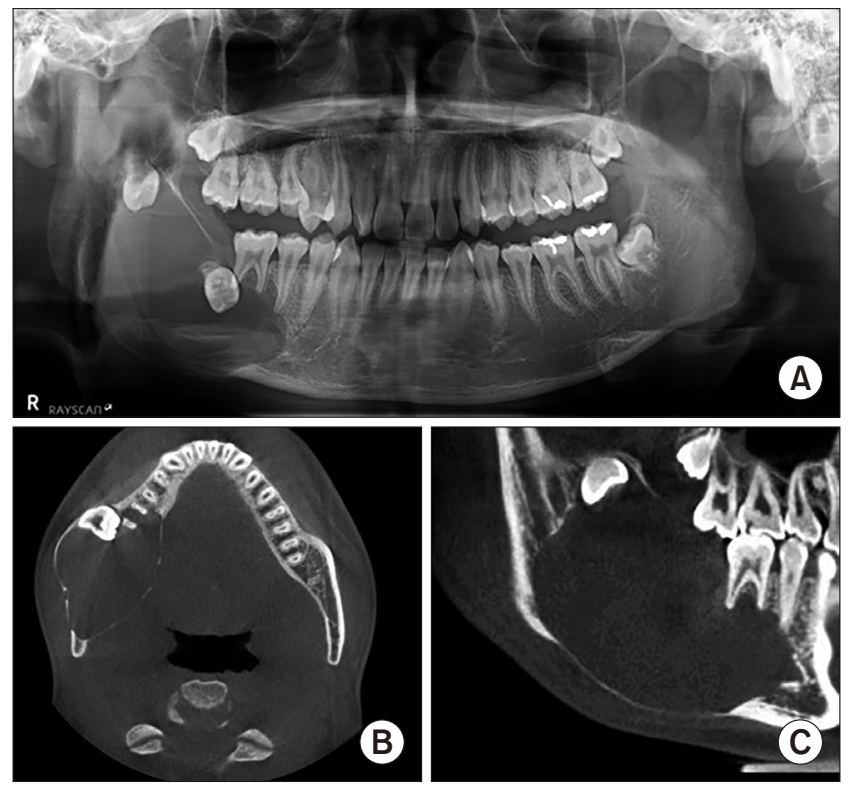

Fig. 6. Radiograph on the first visit. A. Panoramic view (4.5 $\mathrm{cm} \times 8.1 \mathrm{~cm})$. B. Coronal view on computed tomography $(\mathrm{CT})$, mandibular cortical bone was flattened and dilated. C. On sagittal $\mathrm{CT}$, the mandibular inferior border was very thin.

Sang Min Lee et al: Conservative management with Carnoy's solution in ameloblastoma involving two unerupted teeth: a report of two cases. J Korean Assoc Oral Maxillofac Surg 2021

in $\mathrm{CT}$ view. Upon clinical examination, secondary healing of the soft tissue was observed in the open dressing site with furacin gauze of $1.5 \mathrm{~cm} \times 1.5 \mathrm{~cm}$. No paresthesia of the right lower lip area and no recurrence of the lesion were observed during the 10-month follow-up period.(Fig. 9)

\section{Discussion}

Treatment modalities for ameloblastoma include segmental or marginal resection or more conservative treatment with enucleation and curettage. Marsupialization aims to reduce 

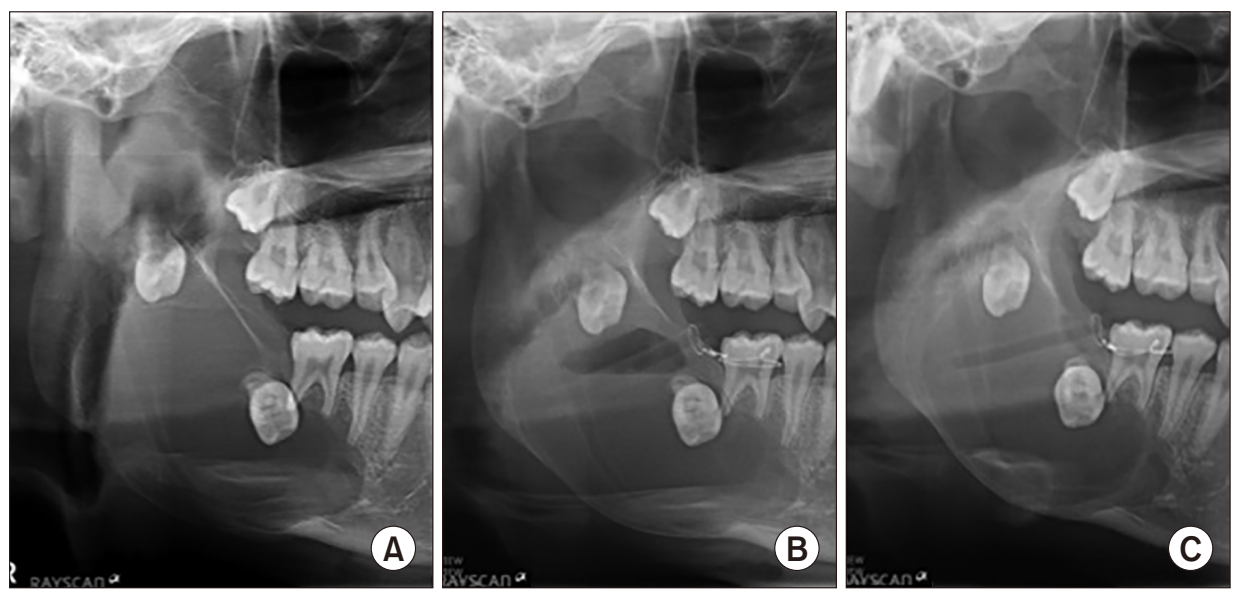

Fig. 7. A. First visit. B. At seven weeks of marsupialization, increase of radiopacity on the superior border of the lesion and woven bone formation on the margin of the lesion were noted. C. At 16 weeks of marsupialization, radiopacity was increased, although the size of the lesion did not exhibit remarkable change.

Sang Min Lee et al: Conservative management with Carnoy's solution in ameloblastoma involving two unerupted teeth: a report of two cases. J Korean Assoc Oral Maxillofac Surg 2021
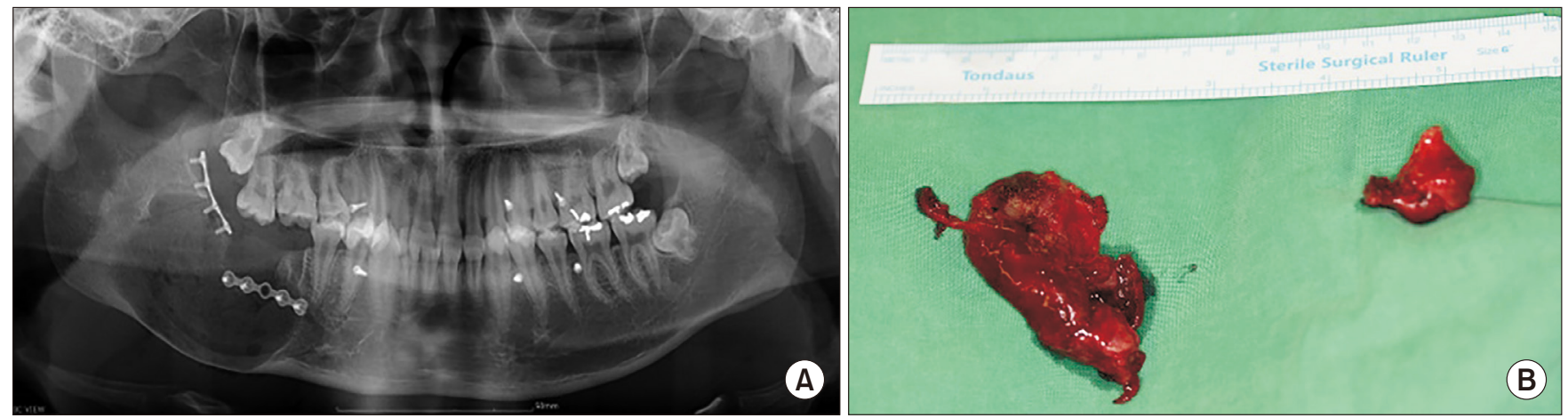

Fig. 8. A. Postoperative panoramic view. B. Removal of the main mass $(4 \mathrm{~cm} \times 5.5 \mathrm{~cm})$ and a small mass $(2 \mathrm{~cm} \times 2.5 \mathrm{~cm})$. Sang Min Lee et al: Conservative management with Carnoy's solution in ameloblastoma involving two unerupted teeth: a report of two cases. J Korean Assoc Oral Maxillofac Surg 2021

lesion size and is followed by secondary surgery ${ }^{11,12}$.

Marsupialization is a "cost-effective" technique for treatment of cysts. However, several disadvantages exist such as patient discomfort at the beginning of treatment and need for patient cooperation. Furthermore, in some cases, a secondstage surgery is required to remove the remaining pathological tissue. Long-term follow-up is required to observe the involved tooth ${ }^{1}$. Hou and Zhou ${ }^{1}$ reported use of tube, gauze, or obturator to perform marsupialization or decompression. Regardless of the device used, the size of the cystic lesion decreased, vital tissue was conserved, and osteogenesis was promoted $^{1}$.

For enucleation performed after marsupialization, information about adequate duration of marsupialization is rare ${ }^{13-15}$. Gao et al. ${ }^{4}$ reported that marsupialization as a primary treatment was effective in shrinking the size of dental cyst and regenerating bone. Even though there was a difference in degree of shrinkage, a significant decrease in the size of the lesions was observed in radicular cyst (RC), odontogenic keratocyst $(\mathrm{OKC})$, and UAB. The standard size of a lesion was defined as the estimate of maximal vertical length $(\mathrm{cm})$ by maximal horizontal length $(\mathrm{cm})$ in panoramic view as determined by two radiologists. Cyst enucleation was performed when cyst size was $<3 \mathrm{~cm}^{2}$ in OKC and RC. However, marginal resection was indicated as a treatment protocol in UAB. In cysts $>3 \mathrm{~cm}^{2}$, decompression was suggested with a minimum opening diameter of $0.8 \mathrm{~cm}$. In addition, Gao et al. ${ }^{4}$ suggested that the duration of decompression should be 2.75 months for RC, 8.32 months for $\mathrm{OKC}$, and 9.14 months for UAB. However, the basis for these specific time periods was not provided ${ }^{4}$. Since both patients included in this study had radiolucent lesion $>3 \mathrm{~cm}^{2}$ in panoramic view, marsupialization was the first option. The size of the lesions decreased during the 12 weeks after marsupialization but showed no further decrease after 16 weeks of follow-up.

In these two cases, the middle of the 16-Fr Foley catheter was cut to an appropriate size and used for marsupialization. The Foley catheter possesses a large hole (approximately 3 $\mathrm{mm}$ in diameter) for urine flow and a small hole (approximately $1 \mathrm{~mm}$ in diameter) for ballooning. With the syringe needle tip tightly engaged with the small hole, saline can be injected with strong pressure and drained through the large 

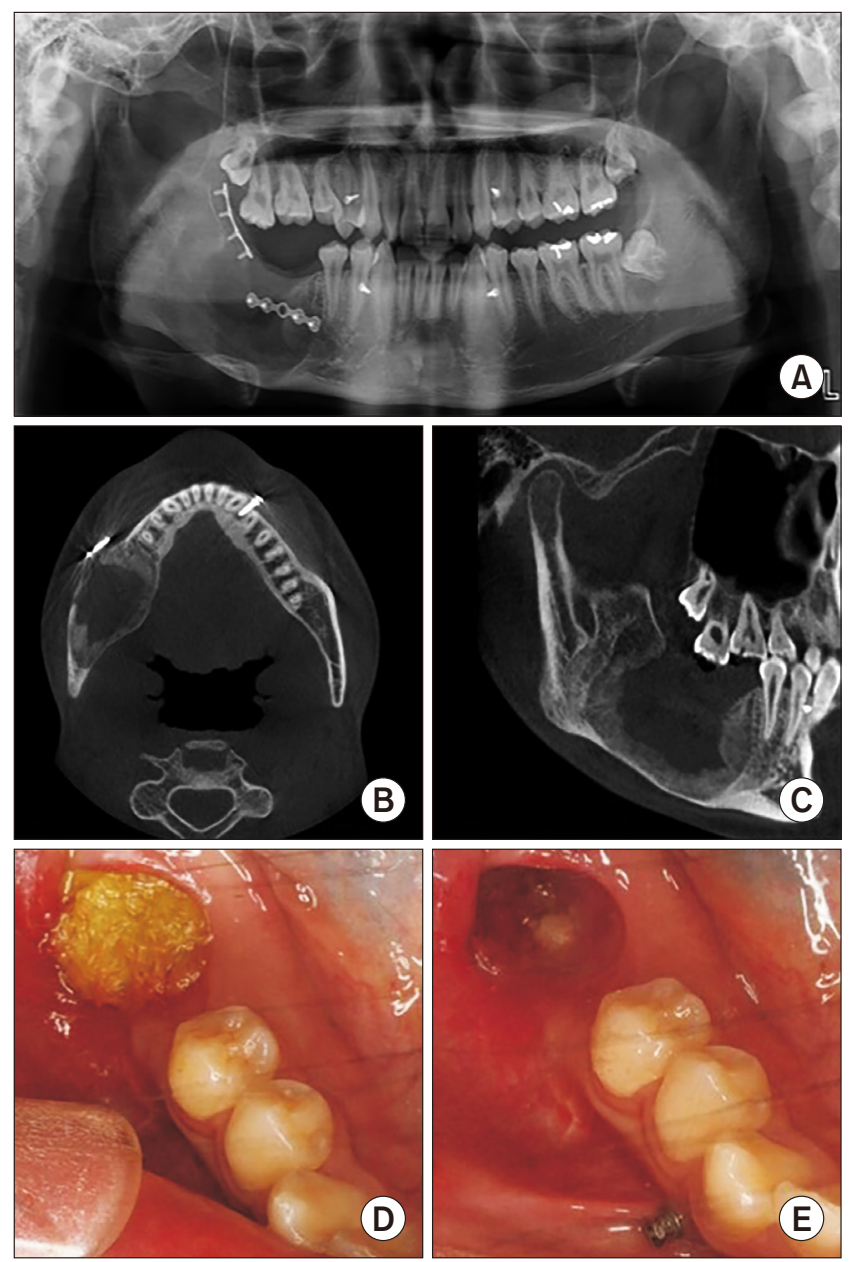

Fig. 9. Radiograph after 22 weeks of marsupialization. A. Panoramic view on \#45 distal, posterior, and inferior borders of the lesion: radiopacity was increased. B. Coronal view on computed tomography (CT): new bone formation was observed along the mass removal area. C. Sagittal view on CT: new bone formation was observed along the mass removal area. D. Intraoral photograph at 22 weeks of cyst enucleation: furacin gauze was changed every week. E. Soft tissue healing was observed after 22 weeks of cyst enucleation.

Sang Min Lee et al: Conservative management with Carnoy's solution in ameloblastoma involving two unerupted teeth: a report of two cases. J Korean Assoc Oral Maxillofac Surg 2021

hole. This two-way system is thought to be relatively effective in irrigating polymorphic neoplasm without bottleneck in the lesion compared to a one-way drainage system such as a Penrose drain tube.

The main components of Carnoy's solution are chloroform $(3 \mathrm{~mL})$, absolute alcohol $(6 \mathrm{~mL})$, glacial acetic acid $(1 \mathrm{~mL})$, and ferric chloride $(1 \mathrm{~g})$. With cotton applicators or ribbon gauze, it is applied to the lesion for 3 minutes while protecting the adjacent soft tissues ${ }^{6,9}$. Carnoy's solution is a powerful fixative agent for remaining tumor cells within the cancellous space $^{11}$. Frerich et al. ${ }^{16}$ suggested that application of Carnoy's solution should not exceed 3 minutes, and that direct applica- tion to the nerve could lead to nerve damage. Carnoy's solution often is used as a complementary treatment for a lesion with a high recurrence rate. If there is nerve exposure in the cavity, solution should avoid the nerve as much as possible and be applied only once ${ }^{10,17}$.

According to a retrospective study of 29 patients by Lee et al. ${ }^{10}$, when Carnoy's solution was applied for 3 minutes after cyst enucleation despite a diagnosis of UAB histologically exhibiting 93\% mural invasion, a low 10\% recurrence rate was reported. This suggests that Carnoy's solution may be beneficial against recurrence.

According to a study of four treatment modalities of UAB by Lau and $\mathrm{Samman}^{18}$, the recurrence rate was 3.6\% for resection, $30.5 \%$ for enucleation alone, $16 \%$ for enucleation followed by application of Carnoy's solution, and 18\% for marsupialization with/without other secondary treatment. Therefore, enucleation with application of Carnoy's solution is the best treatment option other than resection ${ }^{11,18}$.

Lau and Samman ${ }^{18}$ stated that the recurrence rate may be lower than that reported above. If cystic residue remains after attempts to preserve teeth around the cyst, it may lead to recurrence ${ }^{10,11,18}$. Therefore, in the two cases in this report, all the teeth involved in the cystic lesions were extracted, and Carnoy's solution was applied for 3-5 minutes.

In conclusion, in this study, two patients presented to the hospital with an unerupted mandibular second molar. Panoramic radiograph revealed a relatively large radiolucent lesion with two impacted teeth that was diagnosed as ameloblastoma on permanent biopsy. We performed marsupialization as a primary treatment considering the size of the lesion and the age of the patients.

(1) The clinical duration of marsupialization in radiologic size reduction of ameloblastoma involving two impacted teeth was approximated at 12 to 16 weeks. In both patients, there was no reduction in size beyond 16 weeks, and longterm marsupialization was attributed to poor oral hygiene. Using data from only two patients is not sufficient for establishing a standard treatment protocol, and further studies are necessary.

(2) Carnoy's solution was applied in the two patients for approximately 3-5 minutes after enucleation, starting from the last entry site, followed by washing with normal saline. No side effects or recurrence of the lesions was observed during the one-year follow-up.

(3) A number of different materials has been used for marsupialization. In this study, proper length Foley tube was used. This material is not as strong as a metal but possesses 
more rigidity than gauze or a Penrose tube. The Foley tube has a small hole for the syringe tip to irrigate with strong pressure and a large hole to discharge the neoplasm inside the cavity. This two-way system is effective in irrigating polymorphic neoplasms without bottleneck in the lesion compared to the one-way drainage system.

\section{ORCID}

Sang Min Lee, https://orcid.org/0000-0002-6033-426X

Jeong-Kui Ku, https://orcid.org/0000-0003-1192-7066

Dae Ho Leem, https://orcid.org/0000-0001-6735-8275

Jin-A Baek, https://orcid.org/0000-0001-6326-0828

Seung-O Ko, https://orcid.org/0000-0001-7504-7557

\section{Authors' Contributions}

S.M.L. collected the data and wrote the manuscript. J.K.K., D.H.L., and J.A.B. participated in the study design of the research. S.O.K. was involved with the overall conduction of the study. All author read the final manuscript and approved it.

\section{Conflict of Interest}

No potential conflict of interest relevant to this article was reported.

\section{References}

1. Hou R, Zhou H. Articles of marsupialization and decompression on cystic lesions of the jaws: a literature review. J Oral Maxillofac Surg Med Pathol 2013;25:299-304. https://doi.org/10.1016/ j.ajoms.2013.06.007

2. Haq J, Siddiqui S, McGurk M. Argument for the conservative management of mandibular ameloblastomas. Br J Oral Maxillofac Surg 2016;54:1001-5. https://doi.org/10.1016/j.bjoms.2016.07.017

3. Barnes L, Eveson JW, Reichart P, Sidransky D. WHO classification of tumours: pathology and genetics of head and neck tumours. 3rd ed. Lyon: IARC Publications; 2005.

4. Gao L, Wang XL, Li SM, Liu CY, Chen C, Li JW, et al. Decompression as a treatment for odontogenic cystic lesions of the jaw. J Oral Maxillofac Surg 2014;72:327-33. https://doi.org/10.1016/ j.joms.2013.07.035
5. Cahn LR. The dentigerous cyst is a potential adamantinoma. Dent Cosm 1933;75:889-93.

6. Cutler EC, Zollinger R. The use of sclerosing solutions in the treatment of cysts and fistulae. Am J Surg 1933;19:411-8. https://doi. org/10.1016/S0002-9610(33)90796-5

7. Huang IY, Lai ST, Chen CH, Chen CM, Wu CW, Shen YH. Surgical management of ameloblastoma in children. Oral Surg Oral Med Oral Pathol Oral Radiol Endod 2007;104:478-85. https://doi. org/10.1016/j.tripleo.2007.01.033

8. Maia EC, Sandrini FAL. Management techniques of ameloblastoma: a literature review. Rev Gaúcha Odontol 2017;65:62-9. https:// doi.org/10.1590/1981-863720170001000093070

9. Korzhevskiı̆ DE. [Silver nitrate impregnation of internuclear structures in nerve cells following fixation in Carnoy's medium]. Morfologiia 2001;119:67-9. Russian.

10. Lee PK, Samman N, Ng IO. Unicystic ameloblastoma--use of Carnoy's solution after enucleation. Int J Oral Maxillofac Surg 2004;33:263-7. https://doi.org/10.1006/ijom.2003.0496

11. Kalaskar R, Unawane AS, Kalaskar AR, Pandilwar P. Conservative management of unicystic ameloblastoma in a young child: report of two cases. Contemp Clin Dent 2011;2:359-63. https://doi. org/10.4103/0976-237X.91804

12. Nakamura N, Higuchi Y, Mitsuyasu T, Sandra F, Ohishi M. Comparison of long-term results between different approaches to ameloblastoma. Oral Surg Oral Med Oral Pathol Oral Radiol Endod 2002;93:13-20. https://doi.org/10.1067/moe.2002.119517

13. Motamedi MH, Talesh KT. Management of extensive dentigerous cysts. Br Dent J 2005;198:203-6. https://doi.org/10.1038/ sj.bdj. 4812082

14. Martínez-Pérez D, Varela-Morales M. Conservative treatment of dentigerous cysts in children: a report of 4 cases. J Oral Maxillofac Surg 2001;59:331-3. https://doi.org/10.1053/joms.2001.21006

15. Assael LA. Surgical management of odontogenic cysts and tumors. In: Peterson LJ, Indresano TA, Marciani RD, Roser SM, eds. Principles of oral and maxillofacial surgery. Philadelphia: Lippincott; 1992:685-8.

16. Frerich B, Cornelius CP, Wiethölter H. Critical time of exposure of the rabbit inferior alveolar nerve to Carnoy's solution. J Oral Maxillofac Surg 1994;52:599-606. https://doi.org/10.1016/02782391(94)90098-1

17. Sivanmalai S, Kandhasamy K, Prabu N, Prince CN, Prabu CS. Carnoy's solution in the mangement of odontogenic keratocyst. J Pharm Bioallied Sci 2012;4(Suppl 2):S183-5. https://doi. org/10.4103/0975-7406.100266

18. Lau SL, Samman N. Recurrence related to treatment modalities of unicystic ameloblastoma: a systematic review. Int J Oral Maxillofac Surg 2006;35:681-90. https://doi.org/10.1016/j.ijom.2006.02.016

How to cite this article: Lee SM, Ku JK, Leem DH, Baek JA, Ko SO. Conservative management with Carnoy's solution in ameloblastoma involving two unerupted teeth: a report of two cases. J Korean Assoc Oral Maxillofac Surg 2021;47:40-46. https://doi. org/10.5125/jkaoms.2021.47.1.40 